\title{
V.S. SOLOVYOV'S CHARACTERS OF CHRISTIAN IDEAL IN THE HUMANIZATION PROCESS OF RUSSIAN ARTISTIC EDUCATION
}

\section{(C) 2016}

V.I. Bugaev, candidate of philosophical sciences, associate professor of the Chair of Design and Project Technologies Lugansk Taras Shevchenko National University, Lugansk (Lugansk People's Republic)

Abstract. The article explores the development of Russian culture and education symbolism at the end of XIX in a question about «Filioque». The prominent Russian thinker V. Solovyov considered that the unity of spirituality of Christian ideal faith was carried out in the unity of catholic and orthodox Christian churches. He doubted the question of division of «Character of Vera» perception. V. Solovyov notified the ideal of «iconographic art», which was fundamental conception of development of Russian artistic culture and education. Semantic Christian character-kernel is an interpretation of our «Hail Mary» for us. The ideal of this character is incarnated in the divine beginning «through the free exploit of man», adding the faith in Godman and God-flesh (Hail Mary) to the faith in God. This ideal was announced by F. Dostoevsky. The trinity of Christian ideal must have become the background for conscious spiritual development of Russia and all humanity. Essence of beauty symbolism is perceived in the actual available phenomena - nature and art.

The conception of Sofia - Wisdoms of God character influenced the development of the Russian artistic culture and modern education. The character overflows in concepts: reasonable essence, Divine Bosom, Eternal femininity, Basis, law of life, reason, connection of God and created World. The character of Sofia is oriented to the Russian culture and education development, as a future and final phenomenon of Deity. As a founder of Russian Christian philosophy V. Solovyov defined subsequent motion of symbolism of Christian ideal in the synthesis of Orthodox, revivalist and comparative trends. We notice positive motion in Russian modern artistic education.

Keywords: character; Christian ideal; Hesychasm; archaea; icon; Sofia; Character of Vera; God-flesh (Hail Mary); beauty and art; Divine Bosom; Eternal femininity; law of life; Virgo of Iridescent Gate; Love-Enchantress; Tsarina; orthodox tendency; revivalist and comparative trends; comparative trends; spirituality; secularization; truth.

УДК 797.2

\section{РЕТРОСПЕКТИВНЫЙ АНАЛИЗ И СОВРЕМЕННЫЕ ТЕНДЕНЦИИ ФОРМИРОВАНИЯ ТЕХНИКИ ДВИЖЕНИЙ ПЛОВЦОВ НА РАЗЛИЧНЫХ ЭТАПАХ МНОГОЛЕТНЕЙ СПОРТИВНОЙ ПОДГОТОВКИ}

(C) 2016

М.А. Вершинин, доктор педагогических наук,

профессор кафедры теории и методики физического воспитания

М.В. Пинясова, аспирант кафедры теории и методики физического воспитания

Волгоградская государственная академия физической культуры, Волгоград (Россия)

\begin{abstract}
Аннотация. В статье на основе ретроспективного анализа научно-методической литературы анализируются тенденции формирования техники двигательных действий пловцов на различных этапах многолетней спортивной подготовки. Дается описание взаимосвязей техники движений в плавании с базовыми понятиями биомеханики и гидромеханики, исследуются имеющие существенное значение для техники плавания кинематические характеристики, включающие в себя пространственно-временные, временные и пространственные параметры движений спортсмена. В работе рассматривается динамика изменения на различных этапах спортивной тренировки пловцов таких показателей технической подготовленности, как ритм и частота гребков. В результате изучения данных специализированной литературы делается вывод, что на начальных этапах спортивной тренировки рост результатов пловцов происходит благодаря изменению длины шага, а на этапе высшего спортивного мастерства - за счет изменения частоты гребков. Исследуется возрастная динамика длины шага и темпа на этапах начальной подготовки, начальной и углубленной специализации, становление которой проходит в три этапа: 1) овладение техникой плавания на оптимальных амплитудах; 2) постепенное растягивание, удлинение шага; 3) поиск оптимальных соотношений между длиной шага и темпом. На основании изучения прироста длины шага у юных спортсменов в возрасте 9-15 лет делается вывод, что ритмовая основа техники прохождения дистанции в плавании формируется начиная с начального этапа многолетней подготовки.

Ключевые слова: плавание; пловцы; техника движений в плавании; этапы спортивной подготовки; спортивная тренировка пловцов; формирование техники двигательных действий пловцов; длина шага; частота гребков.
\end{abstract}

Ключевое отличие плавания от всех двигательных наземных локомоций связано с тем, что человек реализует движение в непривычной, совершенно иной среде - воде. Спецификой водной среды обусловливаются особенности передвижения человека, которые раскрываются через дефиницию «техника плавания».
В учебно-методической и специализированной литературе представлены различные определения, освещающие особенности техники спортивного движения $[1 ; 2 ; 3]$. При этом, как указывает Л.П. Макаренко [4], под «техникой спортивного плавания одни понимают рациональную систему движений, позволяю- 
щую пловцу реализовывать свои двигательные и функциональные возможности в высший результат при плавании на соревнованиях тем или иным способом». Другие, как отмечают специалисты [1; 5], к технике плавания причисляют еще и умение пловца максимально эффективно координировать и использовать для поступательного движения вперед все внешние и внутренние силы, воздействующие на тело. Данная сторона техники плавания сугубо персонифицирована и взаимосвязана с развитием функциональных показателей пловца, его ключевых технических качеств.

Техника движений пловца тесно связана с его показателями физической подготовленности, возрастными особенностями, запасом накопленных двигательных навыков, степенью тренированности. По мере взросления и поступательного физического развития юных пловцов неизбежно происходит перестройка их технической оснащенности. При этом, как отмечают специалисты [4; 6; 7], именно в детском возрасте надо сформировать основы должной техники плавания, которые в дальнейшем послужили бы фундаментом для достижения высших ступеней технического мастерства.

Описание техники двигательных действий в плавании реализуется через понятийный аппарат педагогики, математики, гидромеханики и т.д. Проблемам биомеханики и гидромеханики плавания посвящено значительное количество работ [7; 8; 9; 10]. Вместе с тем, несмотря на существующие этой области ощутимые успехи, у специалистов не выработано согласованной позиции в подходе к изучению особенностей механизма передвижений.

В контексте целесообразности техника передвижений пловца нацелена на то, чтобы тело спортсмена испытывало минимальное фронтальное сопротивление, а гребущая поверхность порождала наибольшее значение подъемной силы, векторно ориентированной в сторону движения пловца. Как подчеркивает В.Т. Гринев [8], основным двигательным действием в технике плавания является создание внешней силы, вследствие того, что ее свойства и специфический характер влияют на кинематическую структуру гребка (скорость движения, угол атаки, траектория), а ее величина детерминирует степень приложения усилия и силу тяги. Отметим, что техника спортивного плавания не статична и может подвергаться вариациям, равно как и совокупность факторов, влияющих на нее.

Кроль на груди - наиболее быстрый и популярный способ плавания. Рациональность исполнения технических элементов при проплывании дистанции данным стилем в значительной степени достигается благодаря оптимально эффективной работе рук, поскольку руки, вследствие эволюционного развития человека, оказались наиболее адаптированными к гребковым движениям и являются основным инструментом передвижения при плавании кролем на груди.

С движениями рук взаимосвязаны движения туловища, головы, ног и дыхание. Как отмечает В.М. Зациорский [11], в гребке руками можно условно выделить начало и конец цикла, а также фазы цикла, где фаза представляет собой часть движений, которые объединены выполнением конкретной дви- гательной задачи. Фаза в данном случае является единым механизмом создания движущих сил. В современной теории и методике плавания принято выделять следующие фазы гребка: вход в воду, захват, подтягивание, отталкивание, вынос. Данные пять фаз представляют собой рабочую, основную часть цикла, а подготовительной частью цикла является пронос руки по воздуху.

Важную информацию о технике плавания содержат кинематические характеристики, включающие в себя пространственно-временные, временные и пространственные параметры движений [4; 6].

К пространственно-временным характеристикам относят скорость и ускорение. Скорость движения по дистанции составляют внутрицикловая скорость передвижения тела спортсмена и скорость плавания на соревновательной дистанции. Скорость продвижения спортсмена возрастает во время рабочих фаз и понижается в момент совершения подготовительных движений. Кинематические показатели длины дистанции, темпа, скорости плавания и длины шага взаимосвязаны. Для каждого спортсмена существует определенное оптимальное соотношение длины шага и темпа, когда достигается максимально высокая скорость плавания. Исследователи [12; 13] отмечают, что показатели шага и темпа плавания выступают высокоинформативными маркерами во всех периодах тренировки и обучения.

К временным характеристикам причисляются темп движений и длительность выполнения какоголибо технического элемента. Специалисты отмечают, что юные спортсмены обладают более высоким темпом движений по сравнению с взрослыми пловцами.

Пространственные параметры движений, как отмечают исследователи $[10 ; 11]$, включают в себя шаг пловца, траектории звеньев тела, положение тела. Под категорией «шаг» понимается расстояние, преодолеваемое за отдельно взятый цикл плавательных движений. Траектории пространственных перемещений звеньев тела принято разделять на относительные и абсолютные. Относительными называют траектории, спроектированные по отношению к телу спортсмена. Абсолютные - это траектории, которые получены в неподвижной системе координат, при анализе которых учитываются движения конечностями в поступательном движении спортсмена.

В работе Е.В. Ивченко [14] установлено, что у юных спортсменов увеличение скорости плавания с возрастом происходит прежде всего за счет возрастания длины шага. С.П. Шушаков [15], анализируя кинематическую структуру гребка, выяснил, что у 910-летних мальчиков результат в плавании кролем на груди практически напрямую зависит от оптимальных показателей шага, величина которого обусловливается прежде всего оптимальной продолжительностью фазы захвата руками и эффективностью работы ног.

Еще в середине 80-х годов XX века тренеры Германии при работе над повышением уровня технического мастерства стали уделять особое внимание становлению и отработке таких показателей: ритм и частота гребков, согласование и координация плавательных движений ног и рук, длина шага [3]. Опре- 
деленный уровень соотношений данных показателей дает возможность проплыть соревновательную дистанцию при минимальных затратах. Благодаря совершенствованию частоты гребков и шага наблюдается изменение (в сторону увеличения) скорости плавания. Отметим, что на начальных этапах спортивной тренировки рост результатов пловцов происходит благодаря изменению длины шага, а на этапе высшего спортивного мастерства - за счет изменения частоты гребков.

A. Csaig [16] выяснил, что пловцы низкой квалификации не могут управлять изменением длины шага и темпа при постоянной скорости плавания, что указывает на необходимость уже на ранних этапах спортивной подготовки обучать спортсменов произвольно изменять данные параметры. Выявленные отношения между темпом плавания и шагом определяют их в качестве объектов регулярных тренировочных воздействий и дают возможность управлять этими параметрами в процессе совершенствования уровня технической подготовленности.

Изучение динамических характеристик гребка берет свое начало с середины XX века, когда в условиях плавания на привязи были предприняты первые попытки изучения силы тяги с целью дальнейшего динамического анализа. Этот прием в дальнейшем получил широкую практику при изучении проявления силовых качеств [2].

В научных исследованиях используются и другие подходы к изучению и анализу динамических характеристик техники гребка. В.В. Белоковский [17] апробировал вариант фиксации степени изменения прилагаемых усилий с помощью датчиков давления, которые накладывались на гребущий элемент (стопу, кисть). Д.А. Биневский [18] рекомендует для достижения аналогичной цели задействовать тензометрический консольный датчик. Полученные на основе этих методик результаты были использованы для расчета динамических параметров гребка, модельных параметров гребка, возрастных изменений, индивидуального анализа техники. Разработанные в целом ряде работ модельные характеристики и рациональные проекты техники плавания квалифицированных пловцов подразумевают высокое относительно воды положение тела пловца, эффективность и согласованность гребковых движений. Вместе с тем практика свидетельствует, что юные пловцы часто допускают ошибки при движении руками. Специалисты [12; 14] считают, что для юных спортсменов наиболее значимым является не воспроизведение модельных нюансов техники в мельчайших деталях, а овладение схемой, в рамках которой допускается определенное многообразие действий при решении двигательной задачи.

Для овладения техникой удержания тела на поверхности воды и передвижения по водной поверхности человеку необходим навык создания упора. По мнению В.М. Зациорского [11], обучение новому движению должно базироваться на осмыслении основы двигательного действия. Ввиду того что главным техническим условием перемещения по водной поверхности выступает умение создавать упор или силу тяги, методика обучения основам плавания должна опираться на изучение этих движений.

В.Т. Гринев с соавторами [19] предлагает осваивать по частям технику движений руками и начинать этот процесс с освоения навыка создания упора в средней фазе гребка, поскольку именно умение создавать упор способствует в дальнейшем успешному освоению эффективного и рационального гребка.

Умение опираться о водную поверхность и удерживаться на плаву формируется с помощью специальных упражнений, в основе которых лежит движение кисти по траектории «восьмерки». Содержательная сторона этого движения состоит в том, что, перемещая кисть под углом атаки в $30^{\circ}-40^{\circ}$ по траектории «восьмерки», во фронтальной плоскости создается упор, при этом, прилагая одновременно усилия вниз, достигается эффект удержания туловища на водной поверхности. Усилия должны быть оптимальными, в противном случае кисть будет проваливаться в воду [19]. Эти же специалисты рекомендуют в процессе обучения опорному гребку следовать следующим методическим положениям:

- сгибать и разгибать руку в локте;

- продвигая кисть под углом атаки, параллельно поверхности воды, создать упор;

- одновременно прикладывать оптимальные усилия, опираясь на упор;

- при выполнении движений руками создавать упор вблизи туловища, локти отводить назад.

Все вышесказанное позволяет сделать вывод, что процесс формирования техники плавания будет эффективным только при подборе и использовании адекватных средств обучения, учитывающих закономерности гидромеханики и биомеханики передвижения по водной поверхности.

Освоение элементов современной техники движений в плавании имеет существенное значение с позиций достижения высоких результатов в соревновательной деятельности. На различных этапах многолетней спортивной подготовки юных пловцов техника движений претерпевает большие трансформации в контексте изменений уровня силовой подготовленности, строения тела, индивидуальных особенностей, функциональных возможностей спортсмена и иных показателей $[3 ; 4 ; 20]$. Безусловно, техника обучения плаванию носит персонифицированный характер, но вместе с тем имеются устоявшиеся общие тенденции ее становления и совершенствования в процессе многолетней спортивной подготовки применительно к этапам начальной и углубленной специализации [6]. Для достижения в дальнейшем высокого уровня спортивного мастерства на этапе начальной подготовки осуществляется комплексный механизм обучения технике плавания и ее поступательного совершенствования. На этапе углубленной специализации для дальнейшего совершенствования техники плавания реализуется такое же обучение, как и на предыдущем этапе, но при этом еще добавляется постановка индивидуальной техники и стиля плавания в контексте с нюансами телосложения и физической подготовленности конкретного спортсмена. Техника движений в плавании на различных участ- 
ках дистанции обладает своими особенностями, поскольку каждый из отдельных компонентов соревновательной деятельности достаточно самостоятелен и обособлен. Учет данных особенностей весьма существенен в рамках предсоревновательной подготовки пловцов.

Один и тот же показатель скорости в плавании можно достигнуть с помощью сочетания различных величин длины шага и темпа. Для выхода на наиболее высокие скоростные показатели на дистанции существуют оптимальные (для каждого пловца сугубо индивидуальные) соотношения параметров темпа и длины шага [13]. Они зависят от длины дистанции, способа плавания, длины и пропорций тела пловца, уровня его спортивной квалификации, двигательной и координационной одаренности, технического мастерства, используемого варианта техники движений и ряда других факторов. Например, в вариантах техники, используемых при плавании брассом ведущими пловцами мира, применяется механизм позднего вдоха. Он начинается по завершении главной фазы движений рук, в момент, когда локти и кисти двигаются внутрь и сближаются перед грудным отделом. Момент вдоха четко согласован как с движениями плечевого пояса, так и с движениями рук. Поддержание ритма либо его изменение автоматически отражаются на скорости передвижения пловца. Управление скоростным режимом осуществляется в основном за счет изменения амплитуды, темпа и ритма гребковых движений. Скорость прохождения дистанции увеличивается в связи с повышением темпа только до определенного момента - до уровня оптимальных показателей темпа, когда пловец достигает своей индивидуальной максимальной скорости [13]. Спортсмен с хорошей технической подготовкой наращивает темп преимущественно на основе сокращения отдельных фаз гребка - подготовительной и заключительной. При этом он стремится к сохранению пространственных и временных характеристик главной фазы, стараясь в то же время увеличить силу движений и скорость. Вследствие этого импульс движущих сил у такого спортсмена начинает повышаться пропорционально росту темпа. Оптимальный темп прохождения дистанции - показатель сугубо индивидуальный и достаточно консервативный в контексте достигнутого уровня спортивной подготовленности.

На изменение скорости прохождения дистанции существенное влияние оказывает также изменение длины шага, целенаправленное изменение которой взаимосвязано с изменением темпа, что представляет достаточно трудную задачу для пловца. Специалисты отмечают, что взаимосвязь показателей длины шага и темпа очень точно отражает функциональное состояние пловца, уровень его физической и технической подготовленности [21; 22]. Это состояние максимальной мобилизации спортсмена, когда он в наилучшей редакции координирует свои гребковые движения и достигает оптимальной соразмерности темпа и длины шага. Исследователи отмечают, что по мере возрастания скорости плавания происходит сужение диапазона сочетаний длины шага и темпа, которые дают спортсмену возможность плыть при заданном скоростном режиме с наименьшими затратами сил $[13 ; 23]$. При достижении максимальной скорости на дистанции данное сочетание практически единственно. Отметим, что даже высококвалифицированные пловцы не всегда в состоянии поддерживать стабильность длины шага и темпа на всей дистанции пути. Утомление, наступающее на финише, отражается на амплитуде и качестве гребков длина шага постепенно уменьшается. Чтобы удерживать высокий уровень соревновательной скорости, пловцы начинают увеличивать темп плавательных движений. Отдельные мастера высокого класса способны удерживать на финише показатели длины шага в пределах оптимальных величин, менее подготовленным спортсменам такая задача не под силу - у них длина шага заметно снижается [22].

По мнению ряда специалистов и тренеров по плаванию $[21 ; 22]$ возрастная динамика длины шага и темпа на этапах начальной подготовки, начальной и углубленной специализации проходит свое становление в три этапа:

1) овладение техникой плавания на оптимальных амплитудах;

2) постепенное растягивание, удлинение шага;

3) поиск оптимальных соотношений между длиной шага и темпом.

В.П. Бачин [24] в своих работах констатировал, что длина шага имеет наибольший прирост у мальчиков в возрасте 9-12 лет и далее в 13-15 лет. Это дает основания утверждать, что в период с 11 до 12 лет и далее с 13 до 14 лет у юных пловцов проходит аккумуляция различного двигательного потенциала, а далее в интервалах 12-13 лет и 14-15 лет происходит его практическая реализация с сопутствующей данному процессу коррекцией структуры соревновательного упражнения. При этом в 12-13-летнем возрасте коррекция осуществляется посредством увеличения частоты гребков (темпа), а в 14-15-летнем диапазоне - за счет повышения эффективности гребковых движений, что влечет за собой увеличение длины шага. По мнению В.П. Бачина, в возрастном коридоре 8-11 лет скорость прохождения дистанции в значительной степени определяется уровнем технической подготовленности юных спортсменов, а с 15 лет и далее - силовой подготовленностью в воде. Автор отмечает, что у начинающих пловцов в возрасте до 12 лет и шаг, и темп повышаются, оказывая влияние на рост скорости плавания. На основании зафиксированных данных мы разделяем точку зрения В.П. Бачина о том, что ритмовая основа техники прохождения дистанции в плавании формируется начиная с начального этапа многолетней подготовки.

Анализируя влияние длины шага и темпа на скорость плавания юношей и взрослых пловцов общей численностью в 2000 спортсменов, В.Р. Брагина и В.Ф. Китаев [25] пришли к выводу, что для каждого способа плавания характерны определенные темп и длина шага. Отмечается, что с увеличением протяженности дистанции темп падает, а длина шага увеличивается и, соответственно, наоборот - на более коротких дистанциях темп увеличивается, а длина 
шага у пловцов укорачивается. Авторами подмечено, что длина шага у мужчин больше, чем у женщин, на всех соревновательных дистанциях и способах, за исключением стиля плавания брассом, при этом у мужчин темп движений был ниже, чем у юношей, а размер шага длиннее.

Специальная техническая подготовленность в плавании определяется степенью овладения техникой соревновательных действий и спектром упражнений по ее совершенствованию. Обособленным разделом целесообразно рассматривать технико-тактическую подготовленность пловца, представляющую собой компонент специальной технической подготовленности, проявляемый при прохождении соревновательной дистанции. Совершенствование техники избранного способа плавания базируется на механизме освоения техники дополнительных способов плавания, что позволяет избежать ситуации, когда прочно освоенный двигательный навык, ограниченный узкими рамками специализации, становится препятствием для дальнейшей динамики роста спортивных успехов.

Основным параметром специальной технической подготовленности выступает, как подчеркивают специалисты $[3 ; 13]$, эффективность техники действий пловца в условиях соревновательной деятельности. В частности, достаточно объективной оценкой качества и эффективности специальной технической подготовленности считается сопоставление основных ориентиров педагогической модели техники плавания, поворотов и стартов с техникой спортсмена.

Достаточно значимым показателем технической подготовленности в плавании является освоенность техники, проявляемая в способности пловца не снижать эффективность технических действий при наличии внешних (действия соперников, условия соревнований) и внутренних (нарастающее утомление, изменение эмоционального состояния) сбивающих факторов. Чем выше уровень техники пловца, тем качественнее проявляется его способность к поддержанию оптимальных величин длины шага и темпа на протяжении всей соревновательной дистанции в условиях постепенно нарастающего утомления.

\section{СПИСОК ЛИТЕРАТУРЫ:}

1. Каунсилмен Д. Спортивное плавание. М.: Физкультура и спорт, 1982. 208 с.

2. Платонов В.Н. Подготовка квалифицированных спортсменов. М.: Физкультура и спорт, 1986. 286 с.

3. Хальянд В.Б., Тамп Т.А., Каал Р.Р. Модели техники спортивных способов плавания с методикой совершенствования и контроля. Таллин: Таллиннский педагогический институт, 1986.99 с.

4. Макаренко Л.П. Юный пловец. М.: Физкультура и спорт, 1983. 288 с.

5. Сырыщева 3.С. Формирование волевых качеств у подростков при начальном обучении плаванию: автореф. дис. ... канд. пед. наук. М., 1975. 29 с.

6. Булгакова Н.Ж. Отбор и подготовка юных пловцов. М.: Физкультура и спорт, 1986. 190 с.

7. Иссурин В.Б. Формирование спортивно-технического мастерства в водных циклических видах спорта: автореф. дис. ... канд. пед. наук. М., 1989. 25 с.
8. Гринев В.Т. Экспериментальное исследование эффективности гребка, методики оценки и совершенствования техники спортивного плавания: автореф. дис. ... канд. пед. наук. М., 1977. 22 с.

9. Звягинцева Т.М. Биомеханические основы техники гребковых движений в синхронном плавании. Краснодар, 1994. 64 с.

10. Погребной А.И. Научно-педагогические основы начального обучения плаванию в школьном возрасте: автореф. дис. ... д-ра пед. наук. Краснодар, 1997. 37 c.

11. Зациорский В.М. Биомеханика плавания. М.: Физкультура и спорт, 1981. 135 с.

12. Берестецкая Н.Ю. Методика технической подготовки пловцов с учетом возрастных особенностей формирования двигательной функции: автореф. дис. ... канд. пед. наук. Киев, 1987. 24 с.

13. Булгакова Н.Ж. Спортивное плавание. М.: Физкультура, образование, наука, 1996. 430 с.

14. Ивченко Е.В., Шухардин И.О., Крылов А.И. Особенности техники движений у юных пловцов // Совершенствование двигательных действий спортсменов водных видов спорта: Сборник научных трудов. Л., 1989. С. 30-36.

15. Шушаков С.П. Возрастные особенности совершенствования техники движений у юных пловцов-кролистов // Вопросы биомеханики физических упражнений: Сборник научных трудов. Омск, 1993. C. 88-95.

16. Csaig A., Boomer W. Testing your swimmers: stroke rate-velocity-distance per stroke // Swimming World. 1982. № 4. Р. 23-25.

17. Белоковский В.В. Художественное плавание. М.: Физкультура и спорт, 1990. 112 с.

18. Биневский Д.А. Возрастные особенности формирования спортивно-технических навыков у пловцов учебно-тренировочных групп ДЮСШ: автореф. дис. ... канд. пед. наук. М., 1993. 22 с.

19. Гринев В.Т., Погребной А.И., Костюк Ю.И., Звягинцева Т.М. Биомеханические основы обучения плаванию. Краснодар, 1990. 82 с.

20. Фомиченко Т.Г. Совершенствование силовой и технической подготовленности пловцов разных возрастных групп. М.: СпортАкадемПресс, 2001. $103 \mathrm{c}$.

21. Кашкин А.А., Гордон С.М. Плавучесть и обтекаемость юных пловцов различного возраста и пола. М.: РГАФК, 1995. 26 с.

22. Макаренко Л.П. Техника и тактика соревновательной деятельности при плавании способом брасс. М.: РГАФК, 1996. 40 с.

23. Викторов В.Ф. Повышение скорости пловцабрассиста на основе совершенствования структуры движений. М., 1986. 20 с.

24. Бачин В.П. Возрастная динамика темпа и шага и максимальной скорости при плавании спортивными способами у пловцов 8-17 лет // Теоретические и методологические аспекты определения спортивной одаренности: Сборник научных трудов. Омск: ОГИФК, 1989. С. 56-58.

25. Брагина В.О. Влияние «темпа» и «длины» шага на скорость плавания // На голубых дорожках. М.: Физкультура и спорт, 1969. С. 97-107. 


\section{RETROSPECTIVE ANALYSIS AND MODERN TENDENCIES OF SWIMMERS' MOVEMENT TECHNIQUE DEVELOPMENT AT DIFFERENT STAGES OF MANY YEARS SPORTS TRAINING}

(C) 2016

M.A. Vershinin, doctor of pedagogical sciences, professor of the Chair of Theory and Methods of Physical Education M.V. Pinyasova, postgraduate student of the Chair of Theory and Methods of Physical Education Volgograd State Physical Education Academy, Volgograd (Russia)

Abstract. Based on retrospective analysis of scientific-methodical literature the article deals with the analysis of trends of swimmers' movement technique development at different stages of many year sports training. The authors describe the movement technique in swimming with basic concepts of biomechanical and fluid mechanics. Kinematical characteristics including spatial-temporal, temporal and spatial parame-ters of the athlete's movements are investigated. This article considers the dynamics of change of such indicators of technical readiness as rhythm and the stroke rate at different stages of swimmers sport training. Based on data analysis of specialized literature the authors concluded that on the initial stages of sports training swimmers' results increase due to the change in the length of step and at the stage of higher sports skill by changing of stroke rate. The authors study the age dynamics of step length and tempo at the initial training, initial and advanced specialization formation which takes place in three stages: 1) mastering the technique of swimming at optimal amplitude; 2) gradual stretching, the elonga-tion step; 3) search for optimum correlation between stride length and tempo. On the basis of study of step length growth of young athletes aged $9-15$ years, the authors conclude that rhythm-based tech-nology course in swimming is generated starting from the initial stage of long-term preparation.

Keywords: swimming; technique of movements in swimming; stages of sports training; swimmers' sports training; swimmers' motor actions technique development; step length; stroke rate.

УДК 37.01

\section{СПЕЦИФИКА ОБУЧЕНИЯ И ВОСПИТАНИЯ УЧАЩИХСЯ В УСЛОВИЯХ ПОЛИЭТНИЧЕСКОЙ ОБРАЗОВАТЕЛЬНОЙ СРЕДЫ}

(C) 2016

Е.А. Зайцева, кандидат филологических наук, доцент кафедры поликультурного образования

A.B. Нуждин, кандидат педагогических наук, заведующий кафедрой поликультурного образования Самарский областной институт повышения квалификации и переподготовки работников образования, Самара (Россия)

Аннотащия. Одной из важных задач современного российского образования является подготовка человека к эффективной деятельности и общению в поликультурной среде. Различные аспекты поликультурного образования нашли отражение во многих нормативно-правовых документах Российской Федерации. Содержание межкультурной компетентности педагога связано с такими аспектами, как осознание национальнорелигиозных, гендерных и иных особенностей обучающихся, уважительное отношение к ним; способность к культуросообразному поведению; способность организовать конструктивное межкультурное взаимодействие в коллективе и использовать межкультурные различия для обогащения личного культурного опыта обучающихся; знание и учет психологических особенностей восприятия и поведения обучающихся, обусловленных их культурной принадлежностью; способность обеспечивать поликультурную направленность учебновоспитательного процесса, прогнозировать, предупреждать и разрешать межкультурные конфликты в коллективе и т.д. Работа по изучению культуры и традиций разных национальностей в школе должна проходить по разным направлениям: изучение истории народностей и истории присоединения тех или иных народов к России, рассказ о вкладе той или иной этнической группы в защиту своего Отечества; участие детей в национальных и религиозных праздниках; изучение национальной культуры народов (костюма, обычаев, традиций); чтение литературных произведений национальных поэтов и писателей; проведение дней национальных культур; разучивание народных игр; совместные дела класса, школы (конкурсы, соревнования, игры, проекты); работа с семьей, организация семейных вечеров, во время которых поют национальные песни, исполняют стихи на родном языке, предлагают попробовать национальные блюда, рассказывают о семейных и национальных традициях; проведение тренинговых упражнений по воспитанию толерантности и т.д.

Ключевые слова: полиэтническая образовательная среда; поликультурная образовательная среда; поликультурное образование; межкультурная компетентность; культурное многообразие; толерантность; этнопедагогика; этнопедагогические традиции; национальные культуры.

Проблемы образования и воспитания детей в полиэтническом обществе актуальны сегодня во всем мире, поэтому концепции поликультурного образования постепенно завоевывают мировое образовательное пространство. Одной из важных задач современного российского образования яв- ляется подготовка человека к эффективной деятельности и общению в поликультурной среде, что связано с осознанием культурного многообразия, толерантным отношением к этому многообразию и способностью к культуросообразному поведению. 